\title{
Composite System Maintenance Coordination in a Smart Grid Considering Demand Response
}

\author{
Hessam Golmohamadi ${ }^{1} \cdot$ Reza Keypour $^{1} \cdot$ Mohsen Niasati $^{1}$
}

Received: 24 April 2016 / Accepted: 5 October 2016 / Published online: 19 October 2016

(C) Springer Science+Business Media Singapore 2016

\begin{abstract}
Maintenance coordination for a composite power system poses great challenges regarding the manner in which renewable resources and distributed generators can be integrated into the modern competitive power electrical system. Recently, integration of intelligent infrastructures including smart meters and 2-way communication systems increases the complexity of maintenance scheduling problem. The present study is conducted in order to coordinate maintenance scheduling, including generation units and transmission lines, in a smart grid in presence of renewable resources as stochastic power producers. Moreover, by using smart communication service, the study discusses various maintenance strategies which can be optimized by proper demand response. Technically, security and congestion problem are two important issues which are considered in this research. In addition, in order to reduce financial loss of not selling energy during maintenance activities, demand response program is discussed in the maintenance coordination program. To make a reasonable decision under uncertainty, two kinds of important uncertainties are considered in this paper as stochastic power production and random line failure. Regarding the mentioned principles, maintenance scheduling for transmission lines and generation units are coordinated through a smart grid. At the end, a 9-bus test power system is used to show the applicability of proposed maintenance coordination approach which
\end{abstract}

Hessam Golmohamadi

hessam@semnan.ac.ir

1 Department of Power Electrical Engineering, ECE School, Semnan University, Semnan, Iran enables policy makers of power systems to strike a right balance between cost and security in a modern electrical distribution infrastructure.

Keywords Maintenance - Generation unit - Transmission line $\cdot$ Demand response $\cdot$ Smart grid

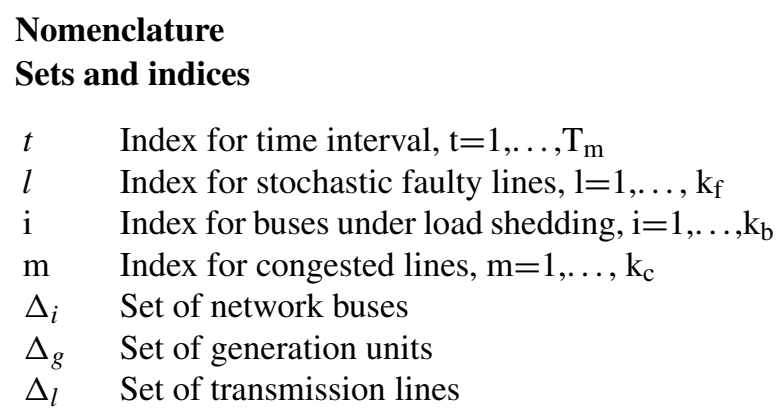

\section{Abbreviations}

DR Demand Response

DSM Demand Side Management

SG Smart Grid

DTL Delay Tolerant Loads

PHEV Plug-In Hybrid Electric Vehicles

DIL Delay Intolerant Loads

FL Flexible Loads

CR Congestion rate

OPF Optimal power flow

CCU Central control unit

LMP Locational marginal pricing

OPF Optimal power flow

FOR Forced outage rate

AMI Advanced metering infrastructure 


\section{Constants and Variables}

$\mathrm{FOR}_{l}^{F} \quad$ Probability of random failure on line / as forced outage rate

$C_{i}^{o} \quad$ Outage cost for bus $i$

$L_{i}^{0}$

$L_{i, k}^{1}$

$C_{n}^{0}$

$C_{n, m}^{p}$

$x_{t}^{p}$

$\bar{M}$

$A_{l, i}$

\section{$\Delta f_{l}$}

$\Delta P_{i}$

$K_{i, T}^{b}$

$\mu \mathrm{L}, \mathrm{i}$

$\rho$

$F_{i j}$

$\bar{F}_{i j}$

$\frac{P(.)}{L_{l}^{D}}$

$L_{i}$

$L_{i}^{T}$

$L_{i}^{I}$

$L_{i}^{F}$
Demand at bus $i$ before load shedding (MW)

Demand at bus i after load shedding due to congestion in line $k$

Power system operation cost with considering no maintenance on generation units/lines

Power system operation cost when equipment $p$ is taken off line for maintenance

Equipment maintenance status [0 01$]$

Maximum number of equipment taken off-line for maintenance in a specific interval Generation shift factor for line / due to change in supply/demand at bus $i$ Change in power flow of line /

Change in supply/demand at bus $\mathrm{i}$

Bonus factor for DTL consumers at bus $\mathrm{i}$

Load shedding priority factor

Congestion occurrence probability

Power flow from bus $\mathrm{i}$ to $\mathrm{j}$ (MW)

Maximum allowable power flow between buses i,j (MW) Probability of (.)

Maximum load shedding level at bus $i$ (MW)

Load at bus $\mathrm{i}$

Delay tolerant part of load at bus $\mathrm{i}$

Delay intolerant part of load at bus $\mathrm{i}$

Flexible part of load at bus i

$\begin{array}{ll}C_{i, T}^{e}(t) & \begin{array}{l}\text { Electricity price for DTL } \\ \text { consumers at bus i and } \\ \text { time t }\end{array} \\ C_{i, F}^{e}(t) & \begin{array}{l}\text { Electricity price for FL } \\ \text { consumers at bus i and } \\ \text { time t } \\ \end{array} \\ K_{i, F}^{b} & \text { Bonus factor for FL } \\ & \text { consumers at bus i }\end{array}$

\section{Introduction}

Maintenance scheduling is one of the most important parts of operation plans that can optimize operation cost and security level of power system if is coordinated properly. When a generation unit is taken off line for doing maintenance, power shortage may be occurred in some parts of power system. On the other hand, doing maintenance on transmission/distribution lines can cause heavy congestion in some weak lines and may result in load shedding to relieve congestion. Carrying out maintenance works on generation units or distribution lines, if an unforeseen failure occurs in a distribution line, the power system security level may be decreased considerably. Moreover, emerging new uncertain production units as renewable resources may increase the complexity of the problem. Inherently uncertain production of renewable resources can pose serious challenges for load management and therefore, affects maintenance coordination strategies in the power system. Decision making for maintenance scheduling under two mentioned uncertainties, including random line failure and uncertain production, needs to be studied comprehensively.

The main target of maintenance scheduling in power system is to strike a balance between system security and maintenance cost [1]. In the traditional vertically integrated power system, maintenance scheduling generally is dispatched by a centralized system operator. With deregulation in power system, privatized generation companies (GenCos) are more pressured to operate in more efficient way to reduce financial loss of not selling energy in maintenance durations [2, 3]. On the other hand, independent power system operator (ISO) is responsible for preserving power system security above a predefined level. Considering the mentioned facts, policy makers of power system faces many challenges to schedule maintenance in a modern power system structure.

Regarding modern structure of power system, paper [4] classified some coordination mechanisms of maintenance scheduling into three categories. In the first category, the ISO coordinated maintenance scheduling based on both GenCos' interest and the power system security [5, 6]. In the second coordination mechanism, positive (negative) 
expense are collected from GenCos as maintenance scheduling cost to dissuade (persuade) them to carry out maintenance in time durations with low (high) level of security [7]. Willingness-to-pay curves (WTP) are discussed in the third coordination mechanism to increase the competitiveness of GenCos to participate in the maintenance scheduling as a game theory [8].

Power system security plays a crucial role in maintenance scheduling. Taking offline a generation unit or transmission line, power shortage or congestion occurrence in weak lines may decrease the power system security. A well-organized maintenance coordination mechanism must guarantee power system security during maintenance activities. Generation adequacy is proposed in [9] as a preventive measure to keep power system reliable. Conventional reliability indexes widely are discussed in different studies to preserve power system security in the maintenance coordination. Loss of load probability (LOLP) is used in [10] as the reliability criteria to determine a reliable margin in the maintenance time intervals. Expected energy not supplied (EENS) and capacity outage probability table (COPT) are discussed in paper [11] to calculate reliability criteria in an interval-based maintenance scheduling approach.

Conventionally, the problem of maintenance scheduling is solved by mathematical programming approach as branch and bound [12], dynamic programming [13] and integer programming [14]. Emerging meta-heuristic optimization approaches and increasing in computational ability of personal computers, the random search methods are widely used in maintenance coordination mechanisms. Recently, particle swarm optimization (PSO) [15], genetic algorithm [16] and simulated annealing [17] have been focused on this problem to find an optimal solution in a nonlinear environment of maintenance scheduling.

Recently, intelligent demand response (DR) and smart grid (SG) have been affected the operation of power system significantly. The growth of advanced metering infrastructure, enhanced communication infrastructure in power grids, and the ability of end-user consumer to actively participate are making the power system more efficient and reliable [18] Therefore, under construction of smart grid maintenance scheduling of power system faces to new challenges. Paper [19] studied a new method for transmission maintenance scheduling to meet the need of smart grid construction. Decision making under uncertainty of smart grid characteristics are discussed in [20]. In this paper, a coordination mechanism between distribution system operator and other market participants, including generation units and ISO is proposed to schedule maintenance in a microgrid.

To sum it up, Table 1 summarizes some main features of distinguished studies about maintenance scheduling in power system [21-33]. As can be seen from the table, considering demand response program and intermittent output power of renewable resources can be interpreted as good ideas for maintenance scheduling in power systems. Considering the mentioned facts, contribution of this paper can be stated as follows:

1) Proposing a coordination program for composite system maintenance including generation units and transmission lines

2) Presenting a method to achieve an optimal maintenance strategy using demand response program

3) Introducing a maintenance approach for smart structure of power system with increased penetration of intermittent wind power.

In this paper maintenance coordination mechanism for a composite power system is proposed considering inherent uncertainties of a smart grid. Stochastic production of renewable resources and probabilistic occurrence of line failure are discussed in this study to increase the applicability of the proposed approach. Regarding the power system security, security cost and congestion cost are proposed in this paper to keep the power system reliable during maintenance scheduling Moreover, by considering high penetration of advanced metering infrastructures (AMI) this paper enables consumers to participate in the maintenance coordination program. The participation of consumers in the maintenance scheduling provides an opportunity for them to shift their flexible demands from maintenance time durations to low electricity price intervals. On the other hand, this preventive measure helps power system operator to preserve system security during maintenance activities. Some improvements in the theory are required that is further discussed in "Conceptual Framework".

The rest of paper is organized as follows. Conceptual framework of the model is introduced in "Conceptual Framework". Formulation of maintenance coordination mechanism is described in "Formulation of Maintenance Coordination Mechanism". The technical formulation of load shedding, security analysis and demand response are described in "Direct Load Control as Demand Response Program" to "Congestion Cost". Numerical results are demonstrated in "Numerical Results". Finally, some concluding remarks are provided in "Conclusion".

\section{Conceptual Framework}

In this paper maintenance coordination between generation units and transmission lines is proposed considering uncertainties associated with stochastic power production of renewable resources and random failure in transmission lines. Taking offline a generation unit or transmission line, optimal power flow (OPF) is run to re-dispatch electrical energy to the new configuration of power grid. In order to 
Table 1 Main features of maintenance coordination techniques in distinguished studies

\begin{tabular}{|c|c|c|c|c|c|c|c|c|}
\hline Ref. & Generation & Transmission & Cost & Reliability & Stochastic/Renewable & Market-based & DR & Solution \\
\hline 21 & $\mathrm{x}$ & $\mathrm{x}$ & $\mathrm{x}$ & $\mathrm{x}$ & & & & Benders Decomposition \\
\hline 22 & $\mathrm{x}$ & & $\mathrm{x}$ & $\mathrm{x}$ & & & & Ant Colony \\
\hline 23 & $\mathrm{x}$ & & $\mathrm{x}$ & $\mathrm{x}$ & & & & Tabu-search \\
\hline 24 & $\mathrm{x}$ & & $\mathrm{x}$ & $\mathrm{x}$ & & & & \\
\hline 25 & $\mathrm{x}$ & & $\mathrm{x}$ & $\mathrm{x}$ & & & & Genetic Algorithm \\
\hline 26 & $\mathrm{x}$ & $\mathrm{x}$ & $\mathrm{x}$ & $\mathrm{x}$ & & & & Mixed integer programing \\
\hline 27 & $\mathrm{x}$ & $\mathrm{x}$ & $\mathrm{x}$ & $\mathrm{x}$ & & $\mathrm{x}$ & & Benders Decomposition \\
\hline 28 & $\mathrm{x}$ & $\mathrm{x}$ & $\mathrm{x}$ & $\mathrm{x}$ & & & & Benders Decomposition \\
\hline 29 & $\mathrm{x}$ & & $\mathrm{x}$ & $\mathrm{x}$ & & & & Duality theory \\
\hline 30 & $\mathrm{x}$ & & $\mathrm{x}$ & $\mathrm{x}$ & & $\mathrm{x}$ & & Genetic Algorithm \\
\hline 31 & $\mathrm{x}$ & & $\mathrm{x}$ & $\mathrm{x}$ & & & & PSO \\
\hline 32 & $\mathrm{x}$ & & $\mathrm{x}$ & $\mathrm{x}$ & & $\mathrm{x}$ & $\mathrm{x}$ & Mixed integer programing \\
\hline 33 & $\mathrm{x}$ & & $\mathrm{x}$ & $\mathrm{x}$ & & $\mathrm{x}$ & & Cob-web theory \\
\hline
\end{tabular}

find the optimum solution(s) for maintenance intervals of generation units and transmission lines, cost and security analysis are implemented during maintenance scheduling process.

Regarding security analysis, random line failure is considered on transmission lines with a related probability. This approach can guarantee power system security during maintenance measures according to N-1 examination of lines. Taking off line a transmission line for doing maintenance, a random failure may occur in some lines and cause heavy congestion in weak lines. In order to find the optimum solution for maintenance of generation units and transmission lines, random line failures are simulated for each maintenance plan. As a result, the maintenance coordination mechanism can propose the maintenance interval for each generation unit and transmission lines with the minimum probability of line failure and congestion occurrence. In order to relieve heavy congestion, load shedding may be essential to preserve power system security. In this paper, a list of priorities for load shedding management is proposed from viewpoint of power system security and operation cost. Through the priority list, the loads with maximum impact on lines congestion and minimum outage cost are chosen for load shedding priorities. Actually, this load shedding approach can guarantee power system security and ensure minimum operation cost for power system during maintenance coordination. In addition, carrying out maintenance works on power system equipment, congestion occurrence poses additional cost to power system due to re-dispatch electrical energy in a sub-optimum way. Finally, a certain value which has two economical and security concepts will be allocated to each maintenance strategy. The economical concept consists of security cost, congestion cost and outage cost as the cost imposed to power system due to load shedding. The security aspect contains security and congestion analysis which is evaluated for each maintenance plan individually. At the end, power system operator can make decision about the optimized maintenance strategy which can guarantee power system security and ensure minimum operation cost.

In order to study under construction of smart grid, it is assumed that consumers can shift their flexible demands during maintenance intervals when power system security may be at risk. In the proposed demand response program (DRPs) the consumers will participate voluntarily into the maintenance coordination mechanism by allowing the system operators to control some of their flexible demands directly during the emergency periods of maintenance intervals On the other hand, system operator allocates incentive bonus to flexible loads which participate in preserving of power system security during emergency periods. Considering the mentioned facts, two kinds of DRPs are discussed in the maintenance coordination programs as direct load control and emergency demand response.

The integration of renewable resources as stochastic producers increases the uncertainty level in power system analysis. In this study, different scenarios with associated probability are discussed for wind generator to overcome the inherent uncertainty of power production. The details are given in the next individual sections.

Figure 1 shows a schematic diagram for proposed maintenance coordination mechanism in a smart grid. 


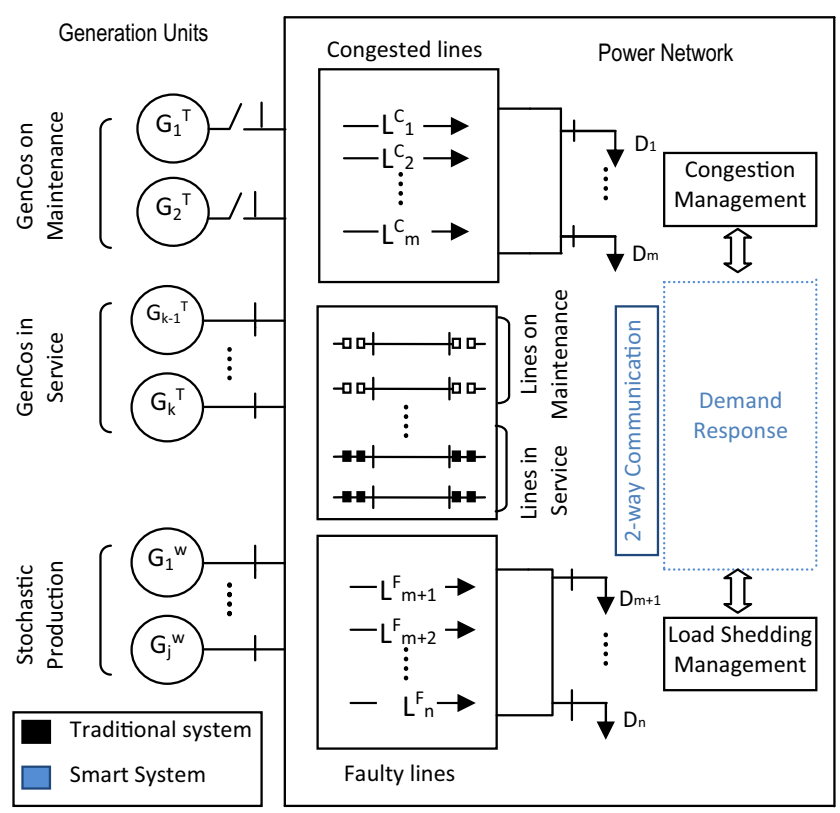

Fig. 1 Schematic diagram of power system in the proposed maintenance coordination mechanism

\section{Formulation of Maintenance Coordination Mechanism}

The maintenance coordination mechanism for composite power system is formulated in this section. The objective function and the related constraints are described as following sections.

\section{Objective Function}

The objective of the proposed coordination mechanism is to minimize the operation cost of power system during maintenance intervals preserving the power system security. As mentioned above, security and congestion costs have two different concepts, economical and security. Therefore, the rational objective function is as follows:

$\operatorname{Min} \sum_{t=1}^{T_{m}}\left[\sum_{l=1}^{K_{f}} F O R_{l}^{F} \times\left(\sum_{i=1}^{K_{b}} C_{i}^{o}\left(L_{i}^{0}-L_{i, k}^{1}\right)\right)+\sum_{m=1}^{K_{c}}\left(C_{n}^{0}-C_{n, m}^{p}\right)\right]$

Where the first term $\left[\sum_{l=1}^{K_{f}} F O R_{l}^{F} \times\left(\sum_{i=1}^{K_{b}} C_{i}^{o}\left(L_{i}^{0}-L_{i, k}^{1}\right)\right)\right]$ shows the security cost.

$C_{i}^{o}$ is the outage cost which is defined for each bus individually. Generally, it is the cost that will be paid to consumers at bus $i$ if load shedding is applied for the bus. The higher outage cost, the importance of load is greater from viewpoint of load management. As a result, the buses with high outage cost are considered as a low priority option in the load shedding management. Probability of random failure on transmission lines describes the probability of stochastic outage (unscheduled outage) and can be extracted from historical data of maintenance crew. To sum up, when a line is taken off line for maintenance, occurrence of random line failure is considered for some transmission lines with a probability value. Congestion occurrence evaluation is implemented in the power system. If heavy congestion occurs in some lines, load shedding is applied according to the prepared load shedding priority list. The details to set load shedding priority list is described in "Load Shedding Priority".

The second term $\left[\sum_{m=1}^{K_{c}}\left(C_{n}^{0}-C_{n, m}^{p}\right)\right]$ describes the transmission congestion charge. The congestion cost is appeared when a generation unit or transmission line are taken off line for doing maintenance and therefore, power system operates in a sub-optimal manner in contrast to the situation that all the power equipment are in service. As a result, when a power equipment is taken off line for carrying out maintenance works, additional cost is imposed to the power system. This cost is the difference between power system operation cost in a quite normal state (all the equipment are in service) and maintenance state (at least one power equipment is under maintenance). The congestion cost is imposed to power system on behalf of the under maintenance equipment including generation unit or transmission lines; therefore, this cost should be considered at the cost related to each maintenance strategy.

\section{Constraints}

The set of constraints related to proposed maintenance coordination mechanism is discussed as follows.

\section{Maintenance Priority}

In many cases, there is a priority list for carrying out maintenance on generation units or transmission lines. There are many reasons for this measure including, seasonal limitations, maintenance crew and resource availability. This may be formulated as follows:

$\sum_{t=1}^{T_{m}} x_{t}^{p}-x_{t-1}^{p^{\prime}}>0$ 
where $x_{t}^{p}$ describes maintenance status for maintenance interval $t$ and power equipment $p$. If $x_{3}^{2}$ takes value 1, (2) enforces that $x_{3}^{3}$ must be zero. It means that maintenance of equipment $p 2$ is in high priority than $p 3$

\section{Maintenance Coincidence}

This constraint implies that in each maintenance interval, a limited number of generation units or transmission lines can be taken off-line for maintenance. The rational reason for this problem is to consider generation and transmission capacity adequacy in maintenance coordination mechanism to prevent from occurring power shortage or heavy congestion.

$$
\sum_{t=1}^{T_{m}} x_{t}^{p} \leq \bar{M}
$$

\section{Network Constraints}

The power flow in each transmission line must be lower that the allowable value. This constraint prevent from occurring heavy congestion in transmission lines. The congestion rate $(\mathrm{CR})$ in transmission network is defined by following probability:

$\rho=P\left(F_{i j} \geq \overline{F_{i j}}\right), \forall i, j$

It is worth mentioning that evaluating the impact of maintenance scheduling on power system security, maintenance coordinator do not only take the generation capacity adequacy, but also transmission capacity adequacy must be considered in maintenance coordination mechanism through $\mathrm{N}-1$ examination of lines.

\section{Load Shedding Constraints}

The load shedding level for each bus may be limited to a predefined level. This can be accomplished by using Eq. 5 .

$L_{i}^{0}-L_{i}^{1} \geq \overline{L_{i}^{D}}, \forall i \in \Delta$

\section{Stochastic Optimal Power Flow}

In this way, in presence of deterministic and intermittent generation facilities (thermal and wind) simultaneously, the problem must be optimized through stochastic optimal power flow rather than deterministic one [41]. The Stochastic Optimal Power Flow S-OPF is formulated as follows [41]:

$$
\begin{aligned}
& \min f(x, u, \bar{\xi}) \\
& \text { s.t. } g(x, u, \bar{\xi})=0 \\
& b^{\min } \leq b(x, u, \bar{\xi}) \leq b^{\max } \\
& u^{\min } \leq u \leq u^{\max }
\end{aligned}
$$

Where:

- $\quad f$ is scalar objective function to be minimized, which is power system operation cost in this paper

- $u$ is the vector of control variables to be adjusted in order to obtain the optimal objective function value. Control variables $u$ in this paper consist of generator active power generations and voltage magnitude at generation buses.

- $\mathrm{x}$ is the vector of dependent variables, which are determined by control variables. Dependent variables $x$ typically include voltage magnitudes and angles at PQ buses, voltage angles and reactive generation at $\mathrm{PV}$ buses, active and reactive generation at slack buses, as well as branch power flows.

- $g$ is the vector of equality constraint functions.

- $\quad \boldsymbol{b}$ is the vector of inequality constraint functions with lower bound ${ }^{\text {bmin }}$ and upper bound $b^{\mathrm{ma}} \mathrm{x}$. Inequality constraints in this paper include the limits of generator reactive capacities $Q g$, branch current magnitudes and load bus voltage magnitudes.

- Vector $\xi$ is the stochastic wind farm generations which is described by Weibull distribution function

\section{Direct Load Control as Demand Response Program}

Taking offline a power system's equipment, a paradigm shift may be needed to maintain power system reliability with ongoing maintenance in power system One of the mechanisms to maintain or improve reliability is enabling the consumers to actively participate directly or indirectly and act as a resource [34]. Active participation of consumers in the electricity market could be achieved through appropriate demand side management programs (DSM). Demand response (DR) can be broadly defined as one of the mechanism within demand side management and possible with ongoing smart grid (SG) activities [18] In this study, direct load control is discussed as DRP to reduce financial loss of not selling energy and preserving power system security. By using direct load control DRP, system operator has the ability to remotely shut down participant equipment on short notice. As with direct load control programs, customers participating in this program receive upfront incentive payments or rate discounts. Participants are asked to reduce their load to predefined values. Participants who do not respond can face penalties, depending on the program terms and conditions.

During the maintenance activities, when a generator or transmission line is taken offline, load shedding is the most conventional event which may be occurred due to power shortage or limited access to transmission network. When a 
load shedding program is performed, system operator has to pay a penalty cost to the consumers. In addition, unplanned overloads may put power system security at risk. For these reasons, by using direct load control DRP, system operator can find out which load buses are the best candidate for direct control during maintenance activities. Therefore, DRP in this situation can reduce financial loss of paying penalty cost to the consumers and preserve power system security. To sum it up, direct load control DRP in the proposed maintenance coordination program can be stated as following steps:

Step1: power system operator run maintenance coordination program to find out which load busses may be shed during maintenance activities, these busses are known as "candidate busses".

Step2: power system operator sends request signal to the candidate busses to ask reduce/cut their load to predefined level in the periods of maintenance activities depending on the program terms and conditions.

Step3: power system operator allocates upfront incentive payment or rate discount for responding consumers and penalizes the consumers who do not respond to the request.

Studying under construction of smart grid, there are three kinds of loads which are considered in the direct load control program as follows:

\section{Delay Tolerant Loads (DTL)}

There are some loads in our daily life which have no strict time request for consumption. These loads can tolerate being served within user defined deadlines, for example, washing-machine or plug-in hybrid electric vehicles (PHEV). Delay tolerant demands can participate in different demand response programs through signing contract with power system operator to providing pre-specified load reduction when the system operator requests. In this way, if the contracted delay tolerant demands respond to the DR program properly, receive upfront incentive payments or rate discounts. In contrast, participants who do not respond can face penalties, depending on the program/contract terms and conditions. This mechanism can guarantee that the contracted demands participate in demand response program according to signed contract with power system operator.

\section{Delay Intolerant Loads (DIL)}

Delay intolerant loads are the load demands which need to be satisfied in the same time slot when they are requested. Regarding this kind of loads, there is no option to shift these loads to lower load level times.

\section{Flexible Loads (FL)}

Flexible loads (FL) are the consumers that make special deals to reduce/cut power consumption when there is an electricity shortage in power network. According to predefined contracts, these consumers agree to consume less power than the predefined pattern when needed in exchange for special benefits. It is most evident that an incentive plan is needed to encourage these consumers to help the power system when an electricity shortage may reduce the power system security. The "incentive bonus scheme" is proposed in this paper to persuade flexible loads to participate in DSM programs.

Now, considering three kinds of loads, we can present a mathematical model for loads in smart grid as following:

First of all, we consider a complex of different loads in different buses:

$\overline{L(t)}=\left[\overline{L_{1}(t)}, \overline{L_{2}(t)}, \ldots, L_{i}(t)\right]$

Each load can be a combination form of three different kinds of demand:

$\overline{L_{i}(t)}=L_{i}^{T}(t)+L_{i}^{I}(t)+L_{i}^{F}(t)$

DT loads can be supplied in a special time duration [t1 t2] which is defined by end-users in smart grid interface:

$L_{i}^{T}(t) \triangleq L_{i}^{T} \mid \begin{aligned} & t_{2} \\ & t_{1}\end{aligned}$

End users can reduce or cut their flexible demands voluntary when there is a request from market operator to preserve power system security:

$L_{i}^{F}(t) \triangleq L_{i}^{F}(t)\left|\begin{array}{|l}t_{2} \\ t_{1}\end{array}+L_{i}^{F}(t)\right|_{t_{3}}^{t_{4}}$

\section{Load Shedding Priority}

In order to minimize forced outage cost, first of all, it must be determined "which buses should be selected for load shedding". The aim of load shedding in the proposed maintenance coordination mechanism is to maintain power system security with lowest outage cost. To achieve this aim two following objects are intended:

1. Selection the load with the most impact on the congested lines: it means that cutting the selected load must result in relieving congestion in transmission lines considerably. This mechanism enforces security constraint for load shedding management.

2. Selection the load with the minimum outage cost: it means that the selected load must have the lowest outage cost in electricity market. This mechanism enforces economic constraint for load shedding management. 


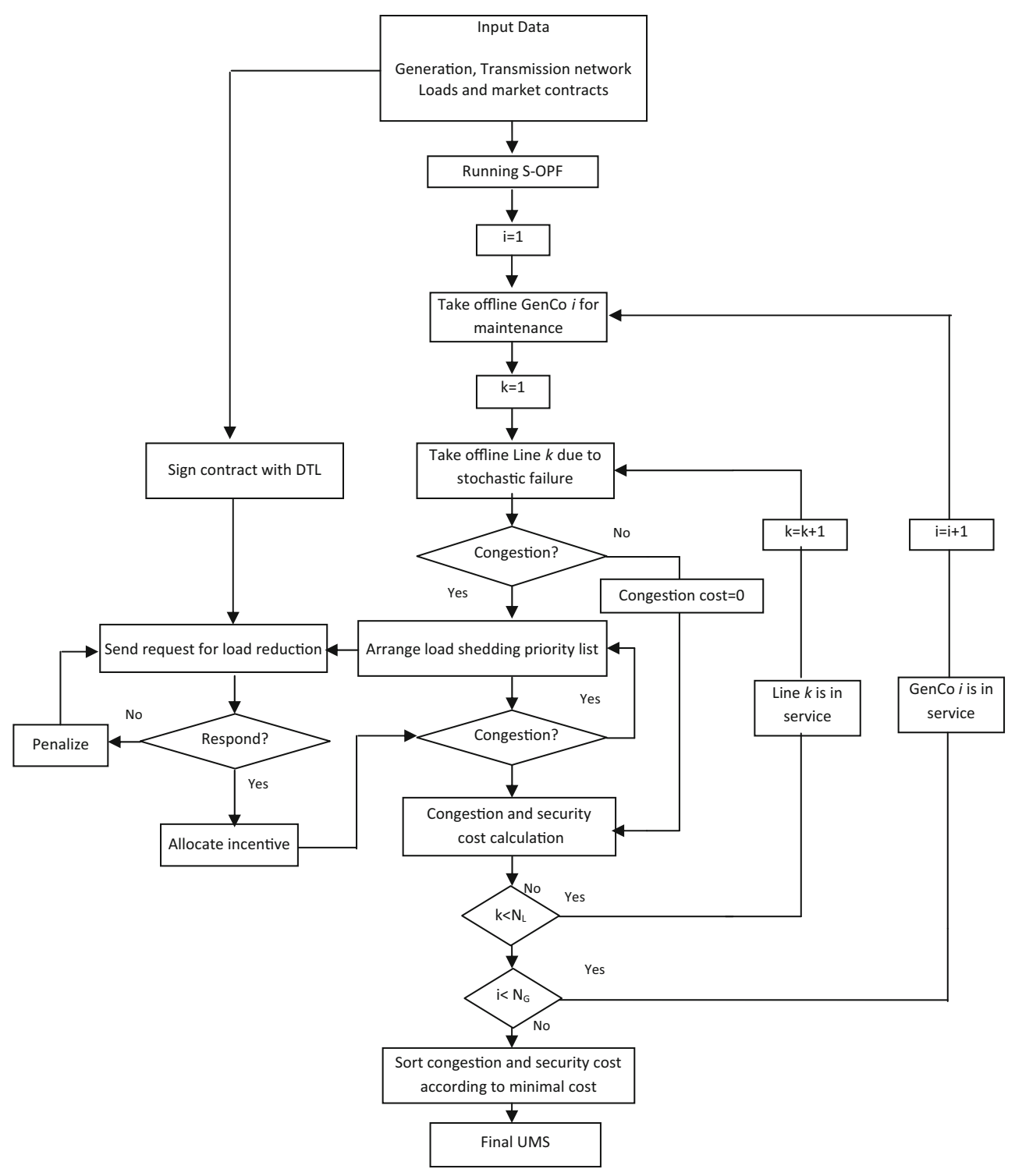

Fig. 2 Schematic diagram of proposed mechanism

In practice, the load shedding technique should be carried out based on a combination of the two mentioned mechanisms. First of all, in order to evaluate the impact of load shedding on congestion relieving, generation shift distribution factor (A factor) is intended. These factors show the approximate change in line flows for changes in generation/bus' load on the network configuration and are derived from the DC load flow. The generation shift factor $A$ is a linear sensitivity factor which indicates the contribution of loads' and generations' power to transmission lines capacity, as following:

$A_{l, i}=\frac{\Delta f_{l}}{\Delta P_{i}}$

It is most evident that $A$ factor may be a negative or positive number (for generation bus $\Delta P_{i}>0$ and for load bus $\left.\Delta P_{i}<0\right)$. Now, in order to relieve the network congestion, load shedding must be done at some buses. For minimizing the load shedding cost, two following objects are intended:

1. Selection the load with the most impact on the congested lines, which means a load with the highest generation shift factor $\left(\mathrm{A}_{\max }\right)$. This factor enforces maximum security level.

2. Selection the load with the minimum outage cost $\left(\mathrm{Ci}_{\text {min }}\right)$. This approach enforces minimum outage cost.

Finally, division of $\mathrm{A}_{\max }$ and $\mathrm{Ci}_{\min }$ determines the load which has the minimum load shedding cost and the most impact on network congestion relieving (high-reliable state). This approach does load shedding which leads to 
Table 2 Thermal generating unit data for 9-bus test power system

\begin{tabular}{|c|c|c|c|c|c|c|c|c|}
\hline \multirow[t]{2}{*}{ GenCo } & \multicolumn{3}{|c|}{$\mathrm{C}\left(\mathrm{P}_{g}\right)=\mathrm{A} \cdot \mathrm{P}_{g}^{2}+\mathrm{B} \cdot \mathrm{P}_{g}+\mathrm{C}(\$ / \mathrm{hr})$} & \multirow{2}{*}{$\begin{array}{l}Q_{\text {gmax }} \\
\text { (Mvar) }\end{array}$} & \multirow{2}{*}{$\begin{array}{l}\mathrm{Q}_{\text {gmin }} \\
\text { (MVar) }\end{array}$} & \multirow{2}{*}{$\begin{array}{l}P_{\text {gmax }} \\
(\mathrm{MW})\end{array}$} & \multirow{2}{*}{$\begin{array}{l}\text { V } \\
\text { (p.u) }\end{array}$} & \multirow[t]{2}{*}{ Maintenance candidate } \\
\hline & A & $\mathrm{B}$ & $\mathrm{C}$ & & & & & \\
\hline 1 & 0.0015 & 7.92 & 561 & 800 & -800 & 1000 & 1.06 & - \\
\hline 2 & 0.00194 & 7.85 & 310 & 100 & -90 & 450 & 1.045 & 2 \\
\hline 3 & 0.00482 & 7.97 & 78 & 100 & -90 & 250 & 1.01 & 3 \\
\hline
\end{tabular}

a cost-effective load shedding management and high security level for maintenance time durations. Therefore, priority factor of each load in load shedding approach is defined as following:

$\mu_{L, i}=\frac{A_{l, i}^{\max }}{C_{i}^{o \min }}$

Therefore, the load with minimum outage cost and maximum generation shift factor is selected for load shedding. Priority list for load shedding is arranged according to incremental rate of "load shedding priority factor $\left(\mu_{\mathrm{L}, \mathrm{i}}\right)$ ". It is most evident that the priority list of load shedding can be interpreted as the best candidate busses for sending load reduction through demand response program.

\section{Security Cost}

Evaluating the impact of maintenance scheduling on power system security, maintenance coordinator do not only take the generation capacity adequacy, but also transmission capacity adequacy must be considered in maintenance coordination mechanism through $\mathrm{N}-1$ examination of lines. When a power equipment is taken offline for maintenance, random failure may occur in a transmission line. In this situation, in addition to power system security, cost arising from stochastic failure may also be incorporated that is called security cost. In order to calculation the security cost, $\mathrm{N}-1$ examination of lines is considered in this paper. In fact, in order to avoid over-optimistic planning, transmission outage should be taken into account. Therefore, target generation unit/transmission line is taken off line in order to perform maintenance and random failure occurs in transmission line simultaneously. As a result, the aim of maintenance coordination mechanism is to find the best solution for maintenance strategy resulting in minimum outage cost (load shedding cost) as following [34]:

$\operatorname{Min}_{F O R, C_{i}^{o}, L_{i}}\left[\sum_{l=1}^{K_{f}} F O R_{l}^{F} \times\left(\sum_{i=1}^{K_{b}} C_{i}^{o}\left(L_{i}^{0}-L_{i, k}^{1}\right)\right)\right]$

The above expression ensures that the coordinated maintenance program with probable random line failure results in minimum imposed cost associated with load shedding management.

\section{Congestion Cost}

When one generator/transmission line is taken off line in order to perform maintenance, the generation point deviates from optimum one and so congestion may occur in some
Table 3 Transmission lines data for 9-bus test power system

\begin{tabular}{lllll}
\hline Transmission line & Connected bus & R (p.u) & X (p.u) & Y (p.u) \\
\hline 1 & $1-2$ & 0.042 & 0.168 & 0.041 \\
2 & $1-4$ & 0.031 & 0.121 & 0.031 \\
3 & $1-6$ & 0.053 & 0.21 & 0.051 \\
4 & $2-3$ & 0.031 & 0.126 & 0.031 \\
5 & $2-4$ & 0.084 & 0.336 & 0.082 \\
6 & $2-7$ & 0.053 & 0.21 & 0.051 \\
7 & $3-4$ & 0.053 & 0.21 & 0.051 \\
8 & $3-9$ & 0.053 & 0.126 & 0.051 \\
9 & $4-5$ & 0.03 & 0.126 & 0.031 \\
10 & $5-6$ & 0.031 & 0.126 & 0.031 \\
11 & $7-8$ & 0.03 & 0.126 & 0.031 \\
12 & $8-9$ & 0.015 & 0.0513 & 0.015 \\
\hline
\end{tabular}




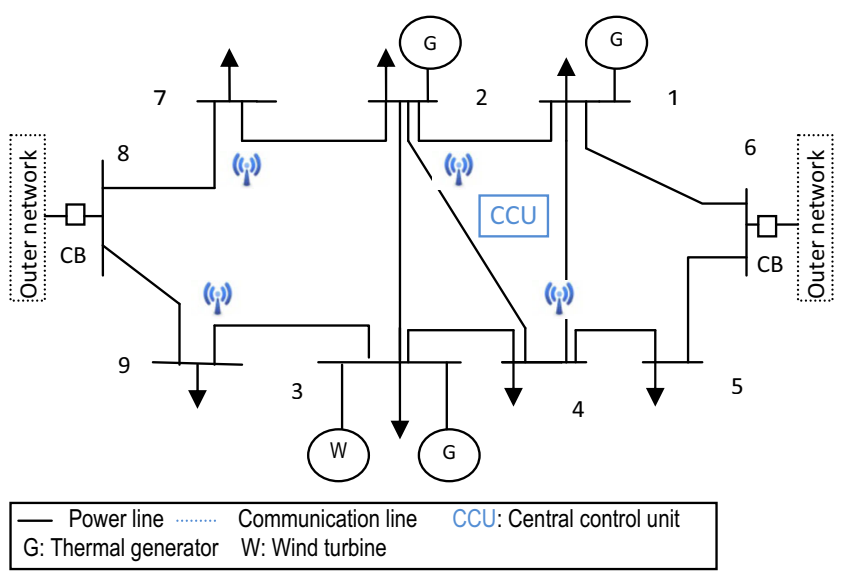

Fig. 3 The 9-bus test smart grid

weak transmission lines. Deviation from optimum generation point and congestion occurrence in transmission lines increases the operation cost of power system. Moreover, congestion occurrence may cause to lose revenue for some generators. Therefore, congestion occurrence can increase the power system operation cost considerably. The basic idea in this proposed method is to consider the cost arising from congestion occurrence associated with each maintenance strategy. In the other words, the cost arising out of maintenance performing of a power system equipment is considered as a part of maintenance cost. Therefore, in the maintenance scheduling, the maintenance strategy with lowest congestion occurrence is coordinated. This approach guarantees the highest possible security and lowest operation cost associated with congestion occurrence.

Computing flows on transmission lines after optimal power flow $(\mathrm{OPF})$ and fitting the flows against unacceptable security level yield cumulative probability of transmission network usage as [35]:

$\operatorname{Prob}\left\{F_{i j} \leq F_{i j}^{\max }\right\}$

Taking offline a generation unit/transmission line, congestion cost is defined as follows:

$\operatorname{Min}_{C_{n, m}^{p}} \sum_{m=1}^{K_{c}}\left(C_{n}^{0}-C_{n, m}^{p}\right)$

The objective of maintenance coordination is to find the strategy resulting in minimum congestion occurrence. This approach can strike a balance between cost (congestion cost) and power system security (congestion rate (CR)) during maintenance scheduling.

\section{Incentive Bonus Involvement in the Demand Response Program}

The key point in the involvement of rewards in the maintenance coordination mechanism is that any smart load participates in preservation of power system security and seeks a consumption pattern with the desirable decision. From consumers' prospective, a desirable decision is the one resulting in minimum consumption cost. This behavior is modeled by the interaction between demand response and incentive bonus scheme. In this approach, flexible and delay tolerant loads submit the amount of desirable-delay/cut tolerated loads for predefined time durations through the smart communication interface between consumers and power system operator. On the other hand, power system operator allocates incentive rewards to these consumers to encourage them to reduce/cut some parts of demands when a
Fig. 4 Load level in maintenance time horizon and different buses

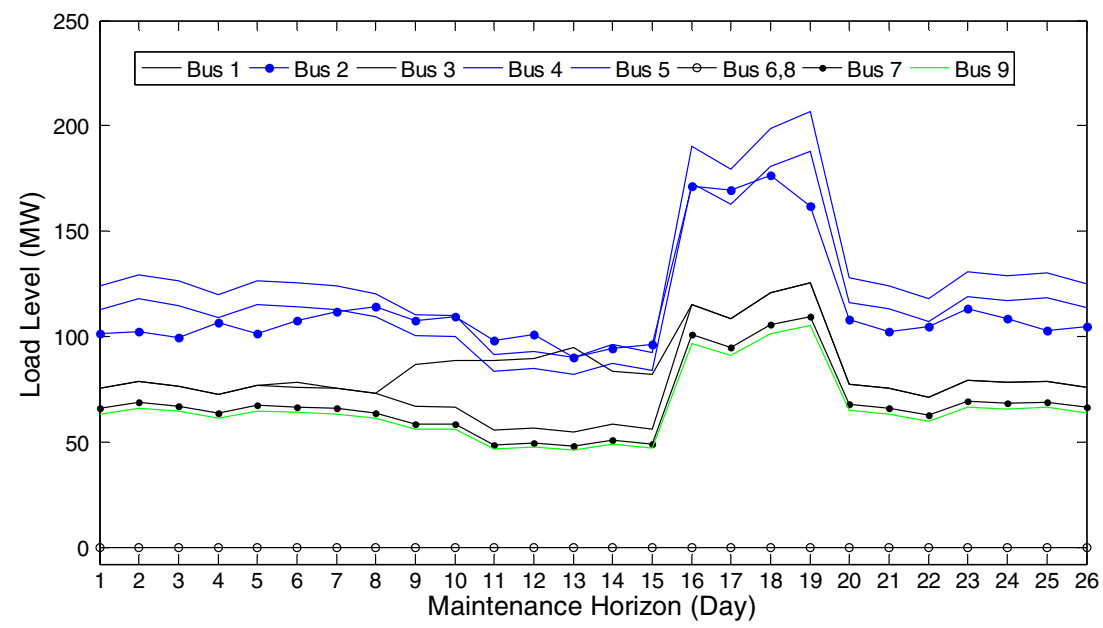


Fig. 5 Probability of scenarios for wind power generation

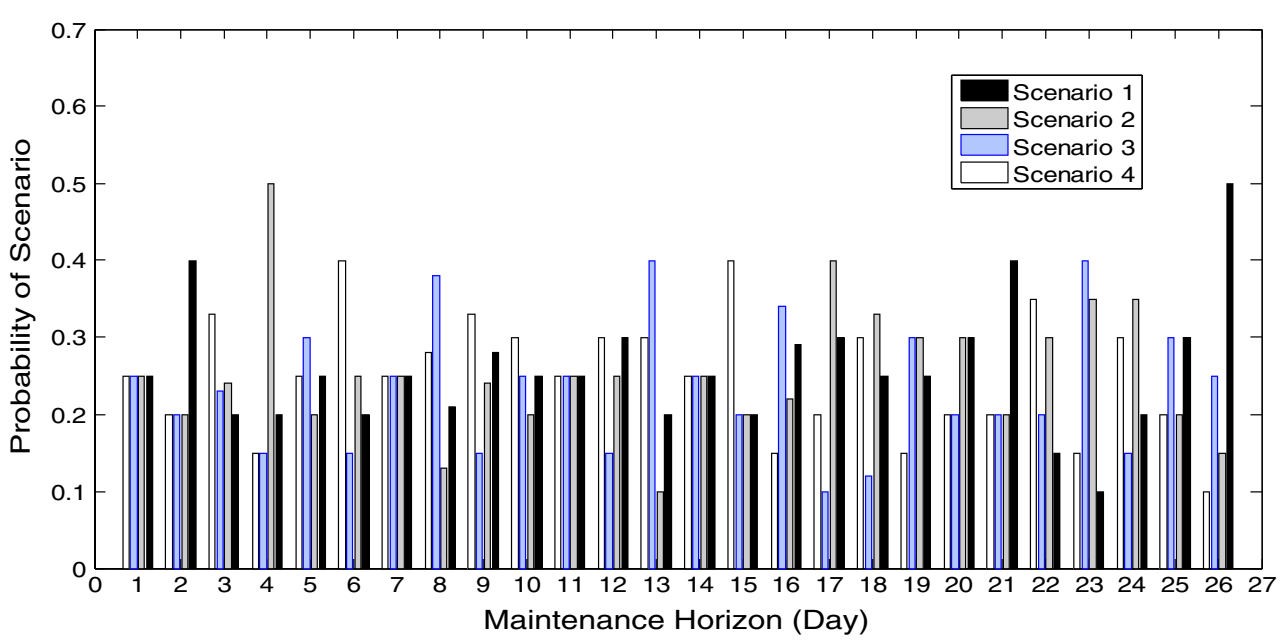

power shortage/congestion may be occurred in power system due to maintenance activities. Therefore, the reward of consumeri as DTL is calculated as follows:

$$
\begin{aligned}
C_{i, T}^{e}(t)= & K_{i, T}^{b} \times \min \left[\left.C_{i, T}^{e}(t)\right|_{t=T_{1}} ^{t=T_{2}}\right]=K_{i, T}^{b} \\
& \times \min \left\{C_{i, T}^{e}\left(t_{1}\right), C_{i, T}^{e}\left(t_{2}\right), \ldots, C_{i, T}^{e}\left(t_{n}\right)\right\} \\
\forall t \in\left[T_{1}, T_{2}\right]= & {\left[t_{1}, t_{2}, \ldots, t_{n}\right] }
\end{aligned}
$$

And the reward of consumeri as FL is calculated as follows:

$$
\begin{aligned}
& C_{i, F}^{e}(t)=K_{i, F}^{b} \times \min \left(\min \left[\left.C_{i, t}^{e}(t)\right|_{t=T_{1}} ^{t=T_{2}}\right], \min \left[\left.C_{i, t}^{e}(t)\right|_{t^{\prime}=T_{3}} ^{t^{\prime}=T_{4}}\right]\right)= \\
& K_{i, F}^{b} \times \min \left\{C_{i, F}^{e}\left(t_{1}\right), \ldots, C_{i, F}^{e}\left(t_{n}\right), C_{i, F}^{e}\left(t_{1}^{\prime}\right), \ldots, C_{i, F}^{e}\left(t_{m}^{\prime}\right)\right\} \\
& \forall t \in\left[T_{1}, T_{2}\right]=\left[t_{1}, t_{2}, \ldots, t_{n}\right],\left[T_{3}, T_{4}\right]=\left[t_{1}^{\prime}, t_{2}^{\prime}, \ldots, t_{m}^{\prime}\right]
\end{aligned}
$$

Regarding delay tolerant loads, market operator allocates the minimum electricity price in the predefined time duration for consumption in the same duration. Moreover, for flexible loads which shift some parts of consumption voluntarily from one time duration $\left[T_{1} T_{2}\right]$ to the other time duration $\left[\mathrm{T}_{3} \mathrm{~T}_{4}\right]$, market operator calculates electricity consumption bills according to minimum electricity price in both time durations. In addition, a bonus factor as $\mathrm{K}=\left[\begin{array}{ll}0 & 1\end{array}\right]$ is considered in this approach to enable market operator to reduce/increase the reward portion of different consumers in various time durations.

To sum up, the proposed algorithm for maintenance coordination is summarized as following steps:

Step1: take offline GenCo $g$ or transmission line 1 for maintenance candidate.

Step2: consider a random line failure on transmission lines with a specific FOR.

Step3: run stochastic optimal power flow.

Step4: calculate balancing between generation and consumption level.

Step5: check power flow in transmission lines.

Step6: if congestion is occurred go to the next step, otherwise go to step 10
Fig. 6 Stochastic wind power generation for scenario planning

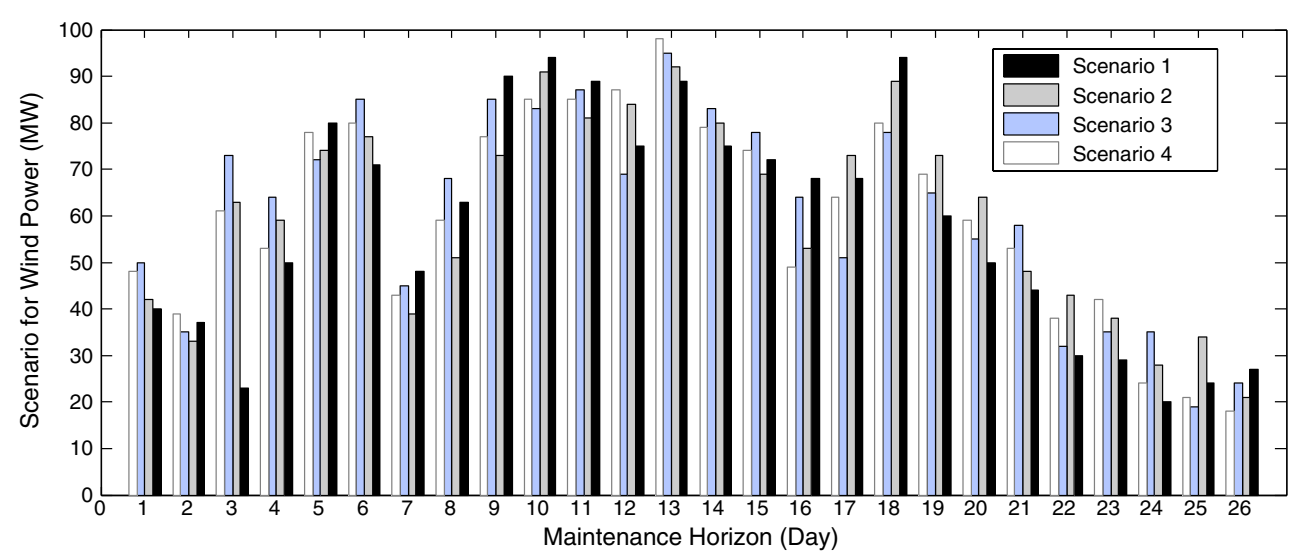




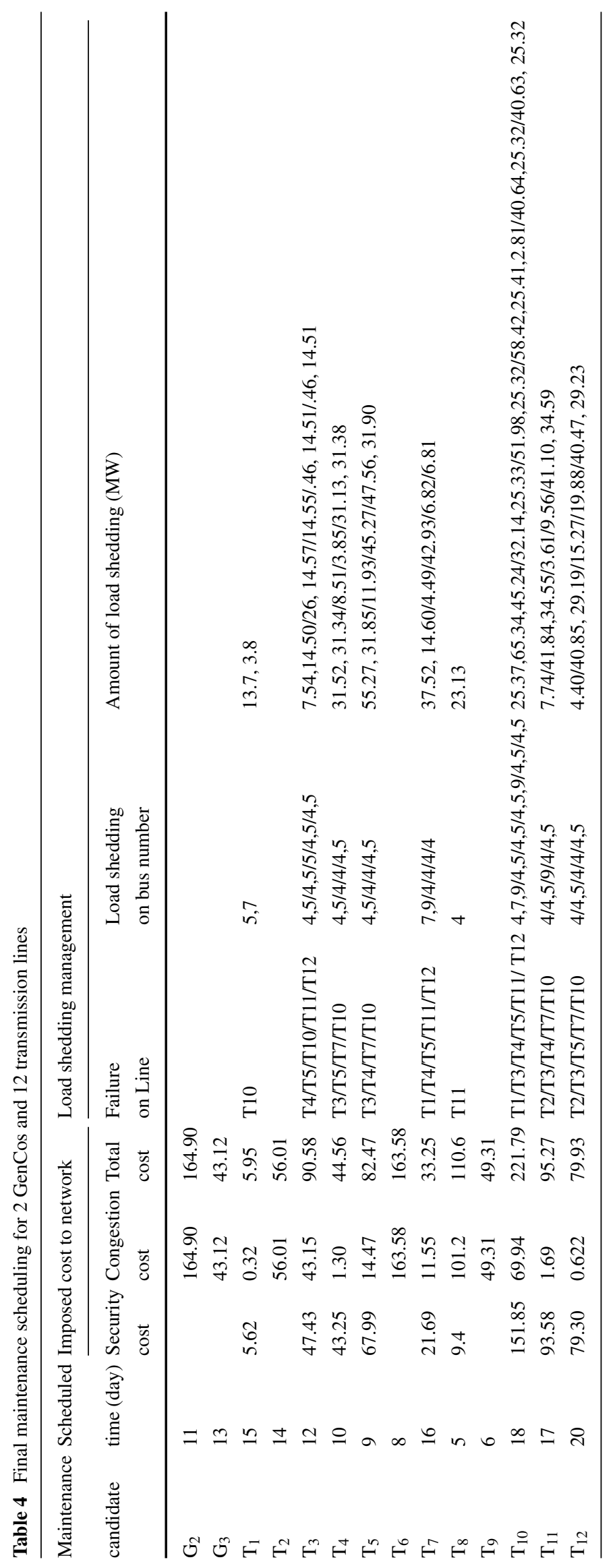




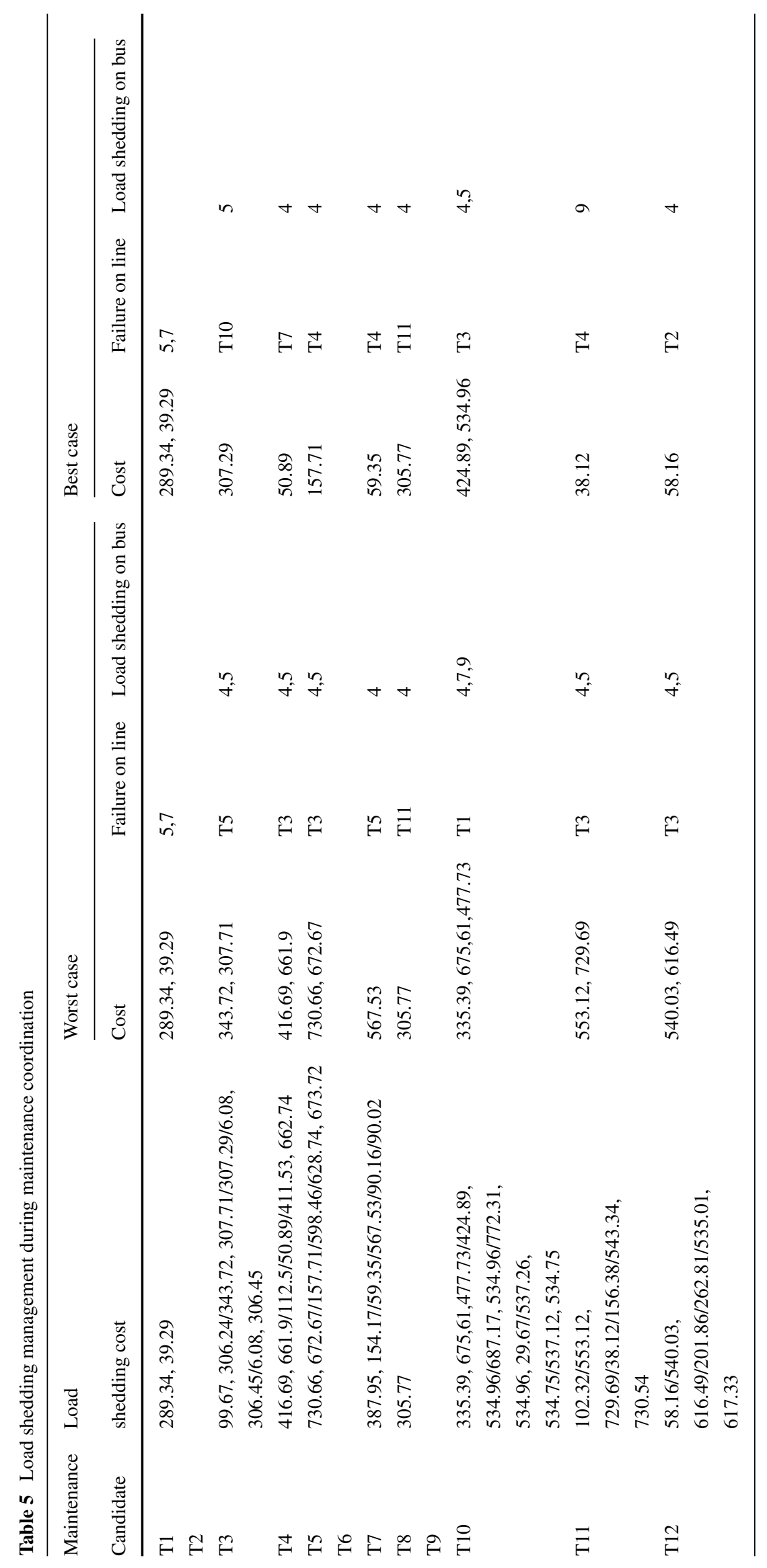


Step7: organize load shedding priority to detect candidate busses for load shedding

Step8: send request signal to DTL or FL consumers to reduce/cut some parts of load.

Step9: implement load shedding program, then back to step 5

Step10: calculate security and congestion cost associated with candidate maintenance strategy.

Step11: select the time interval with lowest cost (security and congestion cost) imposed to power system as final maintenance period for each power system equipment (generator/transmission line).

Step12: allocate incentive scheme for consumers who participate in DRP and penalize consumers who do not respond the request.

Figure 2 describes the procedure of proposed approach in clear and concise manner.

\section{Numerical Results}

Numerical results, based on a 9-bus test power system [36], are reported in this section. The test system details are given in Tables 2 and 3. Moreover, Figs. 3 and 4 shows the diagram of test power system and load level in different buses of power system respectively.

As are seen, the power grid is connected to the outer network through two connecting buses as bus numbers 6 and 8 . It is assumed that there is no electrical transaction between smart grid and outer network. In the other word, the central control unit (CCU) coordinates production scheduling of generation units and consumption pattern of consumers. Carrying out maintenance on power lines/generation units, CCU must keep balance between generation and consumption considering random failure on distribution lines. The communication system enables $\mathrm{CCU}$ to send request to FL and DTL consumers to reduce/cut consumption when a power shortage may be occur due to maintenance activities or random failure. Moreover, the incentive bonus scheme encourages consumers to participate in demand response program which is sent by CCU. Electricity market price for consumers is assumed to be defined according to locational marginal pricing (LMP). For this reason, optimal power flow (OPF) is run and electricity price is calculated for each bus individually. Maintenance time horizon is considered as 26 days. Also, maintenance time duration of each generation unit/line is assumed to be as one day.

Predictions of renewable energy generation can be obtained and presented in a number of different manners. The choice for the type of forecasts and their presentation somewhat depends upon the process characteristics of interest to the decision-maker, and also upon the type of operational problem [37]. In this paper, intermittent output power of wind generation facilities are considered as the main source of uncertainty. In order to overcome uncertainties associated with wind power of intermittent DGs, Auto Regressive Integrated Moving Average (ARIMA) approach [38] is used as scenario generation approach. Moreover, the distribution function of wind speed is regularly considered using a Weibull distribution function. On this basis, in this paper Weibull distribution function has been considered to model the wind speed. Moreover, to calculate produced power, corresponding to specific wind speed, mathematical expression [40] for wind power curve considering cut in, cut out and rated wind speed limitations is used. The number of generated scenario for maintenance time duration is 104 scenarios. In this case, non-seasonal ARIMA $(1,0,1)$ is used to forecast the uncertainties of the wind generation unit. Figures 5 and 6 describe 4 scenarios considered in this paper for probability and generation level of scenarios respectively.

The model is implemented in MATLAB linked with MATPOWER 5.1 [39]

Considering security and congestion cost analysis, Table 4 describes final maintenance scheduling for 2 generation units and 12 distribution lines. In this table, the second column shows the scheduled day for doing maintenance. Columns 3 and 4 describe the security and congestion cost imposed to power system by scheduled maintenance. Satisfying the constraints, the scheduled day for maintenance indicates the day with lowest security and congestion cost which is described by total cost in fifth column. As are seen, carrying out maintenance on line 10 and GenCo 2 imposes the most cost to power system as 221.79 and 164.90 \$ respectively. It is most evident that the imposed cost depends on some power system characteristics, i.e., configuration of power system, location of candidate line/generation unit in power system and forced outage rate of equipment. However, transmission lines 10 and 11 impose the most security cost to power system as 151.85 and 93.58 respectively. Besides, the most congestion cost is arising from GenCo 2 and line 6 as 164.9 and 163.58 $\$$ respectively.

The sixth column demonstrates the probable failure on transmission lines. Extracting the failure rate for transmission lines is dependent on historical data of maintenance crew and maintenance sheets. Considering the mentioned fact, this column describe the most probable line failures on a transmission line when a specified line is taken offline for doing maintenance.

Regarding demand side management, two case studies are considered in this paper. First of all in case study 1, it is assumed that there is no communication and CCU in the power system. In this traditional power system, if a power shortage occurs due to carrying out maintenance on a generation unit or a heavy congestion happens due to line 
Table 6 Proposal for demand response program in FL and DTL consumers

\begin{tabular}{|c|c|c|c|c|c|c|c|c|c|}
\hline \multirow[t]{4}{*}{ Bus No. } & \multicolumn{3}{|c|}{ Delay tolerated loads } & \multicolumn{6}{|c|}{ Flexible loads } \\
\hline & \multirow[t]{3}{*}{ Load level } & \multicolumn{2}{|l|}{ Delay } & \multicolumn{3}{|c|}{ First interval } & \multicolumn{3}{|c|}{ Second interval } \\
\hline & & \multirow[t]{2}{*}{ From day } & \multirow[t]{2}{*}{ To day } & \multirow[t]{2}{*}{ Load level } & \multicolumn{2}{|l|}{ Delay } & \multirow[t]{2}{*}{ Load level } & \multicolumn{2}{|l|}{ Delay } \\
\hline & & & & & From Day & To Day & & From Day & To Day \\
\hline 4 & 6.4 & $12 / 10 / 9 / 16 / 5 / 18 / 17 / 20$ & $21 / 24 / 26$ & 2.9 & $12 / 18$ & $21 / 3$ & 4.9 & $12 / 18$ & $21 / 24$ \\
\hline 5 & 5.7 & $15 / 12 / 5 / 9 / 18 / 17 / 20$ & $21 / 25$ & 4.44 & $15 / 18 / 20$ & $25 / 26$ & 5.43 & $15 / 18 / 20$ & $24 / 26$ \\
\hline 7 & 6.32 & $15 / 16 / 18$ & $7 / 19$ & 6.19 & 18 & 24 & 4.3 & 18 & 24 \\
\hline 9 & 5.7 & $16 / 17 / 18$ & $1 / 4$ & 4.44 & 18 & 23 & 5.32 & 18 & 23 \\
\hline
\end{tabular}

failure, power system operator has to cut some loads to preserve power system security. Secondly, in case study 2, the power system is equipped with communication system and CCU. In this smart grid, power system operator can coordinate maintenance scheduling with smart load to prevent load shedding. In the other word, system operator determines the risky time intervals and sends request to FL and DTL consumers to shift/cut some parts of loads in defined time durations. In this mechanism, probability of load shedding reaches to the minimum point.

Considering case study 1, columns 7 and 8 illustrate load shedding management when a line failure occurs in transmission lines according to sixth column. As are seen, lines 10,3 and 12 have resulted in the most volume of load shedding during maintenance coordination respectively.

Table 5 demonstrates the cost of load shedding for two scenarios including best case and worst case. In the best case the line failure which has been resulted in the lowest cost of load shedding is described. On the contrary, the worst case shows the line failure which imposed the highest load shedding cost to power system. For example, carrying out maintenance on line3 (T3), the highest load shedding cost has arisen when a line failure occurs on line 5 (T5); as a result, it has been resulted in load shedding in buses 4 and 5 with cost 343.72 and 307.71 respectively.

As the worst case reveals, occurring failures on lines 3 and 5 have the most impact on high cost of load shedding. Therefore, the most volume of load shedding is happen in buses 4 and 5 in this case; as a result, buses 4 and 5 can be an appropriate candidate to cooperating demand response. However, the buses 7 and 9 have been experienced load shedding in one case. Consequently, the CCU should send request to the consumers at these buses to cut/shift some parts of load during maintenance duration to preserve power system security and prevent load shedding. Adversely, in the best case, for failure on different lines, load shedding is occurred in buses 4,5 and 9. Considering the worst and base case analysis, buses 45,7 and 9 are the best candidate buses to locate FL/DTL consumers. Therefore, the $\mathrm{CCU}$ should allocate incentive bonus scheme for consumers at these buses to encourage them to shift/cut some parts of loads during maintenance coordination.

After performing security and congestion analysis under maintenance coordination mechanism, candidate buses will
Fig. 7 The impact of maintenace on electricity price (GenCo 1,2 and lines 1-5)

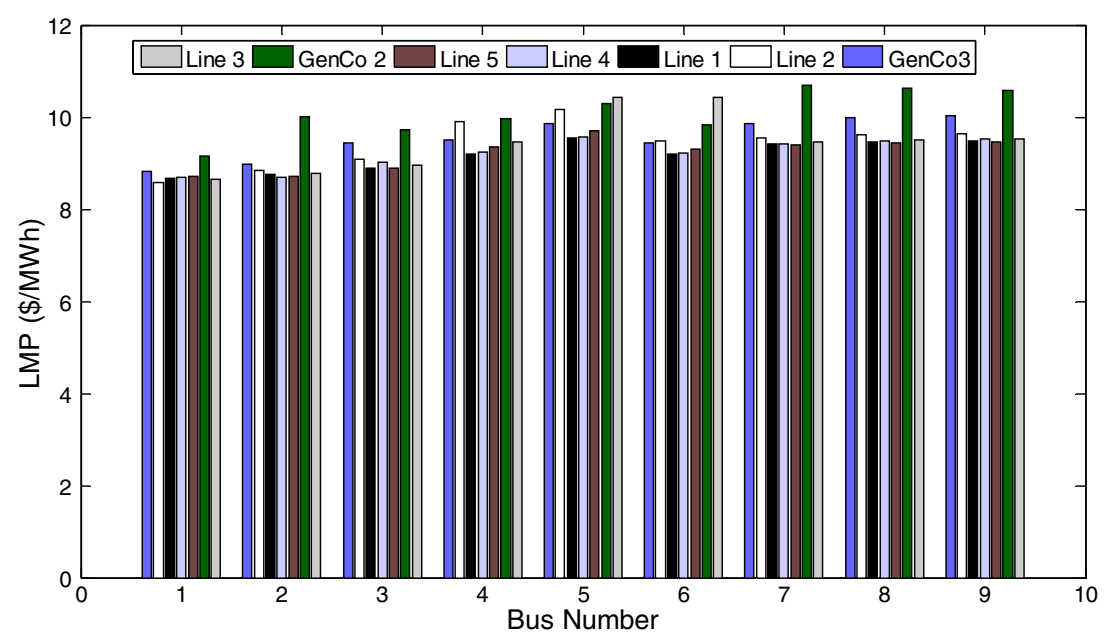


Fig. 8 The impact of maintenace on electricity price (lines 6-12)

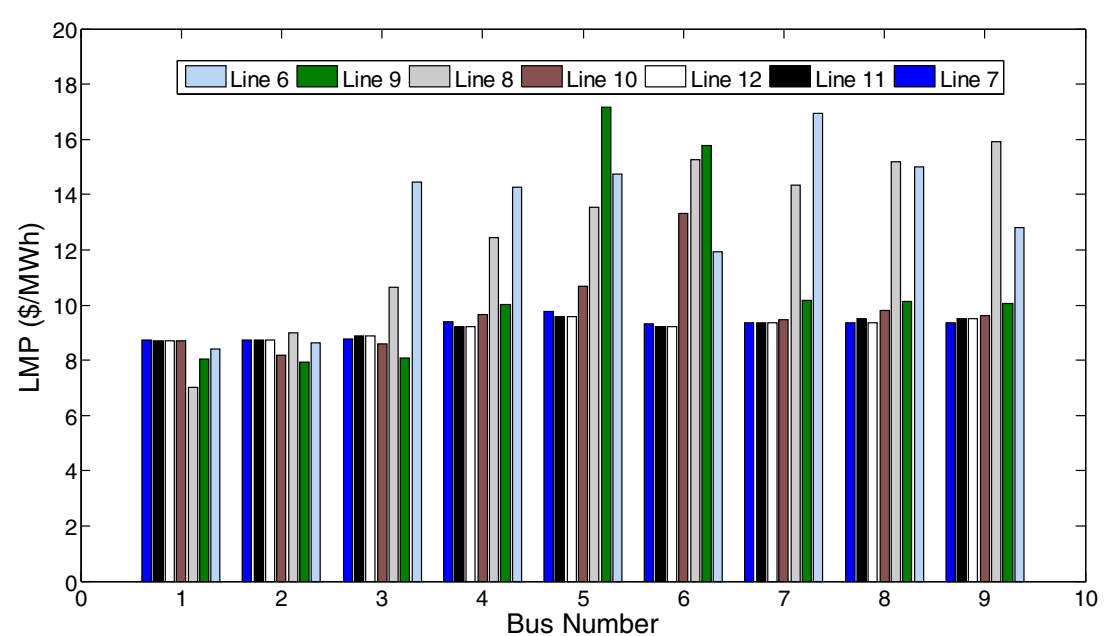

be identified to be considered in demand response program as FL/DTL consumers. These buses are the best candidates for sending request signal by CCU when the power system may be at risk due to line failure or maintenance activities. Table 6 illustrates a proposal which is made according to security and congestion analysis of power system for candidate buses. This table reveals the amount of load at buses 4, 5, 7 and 9 which can be shift from one time duration to the other time durations. For example, DTL consumers at bus 7 has been agreed to shift $6.32 \mathrm{MWh}$ of the demand from high risk time durations as days 15, 16 and 18 to low risk durations as days 7 and 19. These candidate days are chosen by cost and security analysis as mentioned before. In this case, the days 15, 16 and 18 are scheduled for maintenance and load shedding is inevitable if a single contingency is occurred in transmission lines; as a result; these time durations are defined as high risk intervals and are an appropriate candidate to allocate incentive bonus schemes.
Adversely, the time duration with no scheduled maintenance can be identified as low risk durations. Regarding the FL consumers, this kind of loads can be defined as two intervals for shifting loads. The flexibility of FL consumers helps the power system operator to coordinate maintenance with higher degree of freedom. The second part of Table 6 describes the demand side management program for FL consumers during maintenance horizon.

Figure 7 and 8 show the impact of maintenance coordination on electricity price at different buses of power system as LMP. In the analysis the average of LMP in maintenance horizon (26 days) are used. In Fig. 7 the impact of maintenance on GenCos 2, 3 and lines 1-5 are described. In Fig. 8 the impact is investigated for lines 6-12. Regarding the generation units, the outage of GenCo 2 has increased the electricity price in all buses considerably. Considering the transmission lines, carrying out maintenance on lines 9, 6 and 8 has increased the electricity price of power system
Fig. 9 Economic loss of power system operator for two case studies

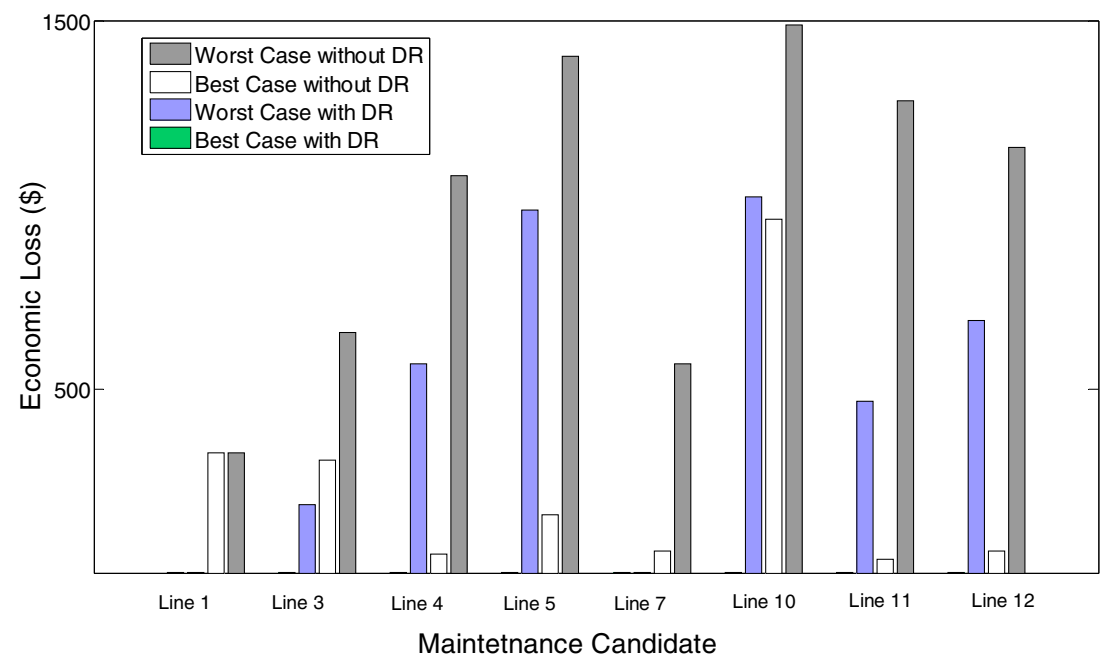


noticeably. To sum up, GenCo 2 and lines 6,8 and 9 can be identified as the power equipment which their maintenance can cause a huge increase in electricity price.

Figure 9 makes a contrast between two case studies from perspective of financial flow. In this figure, economic loss of power system operator in two kinds of power system, including traditional power system without demand response and smart grid with considering demand response, are described. Economic loss of power system operator refers to load shedding cost which must be paid by system operator to the consumers. For example, when line 10 is taken offline for maintenance, in the traditional power system the economic loss are about 959 and 1488 \$ for best and worst case respectively. For this line, by executing demand response, the economic loss of system operator declines to just under 1000 and $0 \$$ for worst and base case respectively, a reduction of $48.8 \%$ and $100 \%$ for two cases.

We can see a similar pattern in the rest parts of chart, which shows a noticeable reduction in economic loss of power system operator. Regarding the demand response, the economic loss for best case is approximately zero for all maintenance strategies of transmission lines. Meanwhile, the economic loss of worst case in demand response program has a downward trend in comparison with the similar case in traditional power system. This is why the approach of observing the impact of demand response on maintenance scheduling is introduced in this paper.

\section{Conclusion}

An optimization based maintenance coordination algorithm was proposed in which the effect of smart grid and demand response on maintenance scheduling was taken into account. Considering two-way communication system in a smart grid, a bilateral transaction was established between power system operator, from one side, and the consumers equipped with smart systems, from the other side. Assigning the incentive bonus scheme from the former side and observing the demand response to access a lower electricity price by the latter side, guaranteed reaching an maintenance scheduling whereas the overall cost imposed to power system are minimized. Moreover, allocating the incentive bonus to the consumers encourages them to participate in demand response program to reduce their electricity bills. Technically, considering security and congestion analysis during maintenance coordination, ensures the maintenance scheduling with reasonable high degree of power system security. Besides, considering random line failure through forced outage rate, provides an opportunity to analyst the maintenance strategies in the worst and base states. Numerical results showed that allocating incentive bonus to the consumers in a smart grid, encourages them to improve the consumption pattern when the power system may be at risk. To sum it up, the proposed maintenance coordination algorithm can strike a balance between power system security and cost; so that it can guarantee power system security during maintenance coordination and ensure fairness among consumers through allocating bonus scheme. In spite of the mentioned facts, some problems still remain for future research, such as using stability constraints in maintenance coordination problem rather than steady-state ones.

\section{References}

1. da Silva EL, Schilling MT, Rafael MC (2000) Generation maintenance scheduling considering transmission constraints. IEEE Trans Power Syst. 15(2):838-843

2. Davoudi M, Cecchi V, Agüero JR (2014) Increasing penetration of distributed generation with meshed operation of distribution systems. North American Power Symposium (NAPS), pp 16

3. Golmohamadi H, Ramezani M (2013) Generation unit maintenance scheduling in power market based on fairness and competition. IEEE conference publication on 21th ICEE, pp 16

4. Wong G, Lu CY, Chung KP, Wen F (2008) Unit maintenance scheduling coordination mechanism in electricity market environment. IET generation transmission and distribution, pp 646654

5. Wang Y, Handschin E (1999) 'Unit Maintenance scheduling in open systems using genetic algorithm. In: Proceedings 1999 IEEE Transmission and Distribution Conference, New Orleans, pp 334339

6. Cai L, Wu B (June 2003) A Regulation for congestion of generator maintenance in a deregulated system. In: Proceedings 2003 IEEE Power System Technology Conference, Piscataway, pp $23-$ 26

7. Conejo AJ, Garcia-Bertrand R, Diaz-Salazar M (2005) Generation Maintenance scheduling in restructured power systems. IEEE Trans Power Syst 20(2):984-992

8. Golmohamadi H, Ramezani M, Falaghi H (2014) Competitive unit maintenance scheduling in deregulated environment based on preventing market power. Turkish J Elec Eng Comput Sci: 22

9. Kim J, Geem ZW (2015) Optimal scheduling for maintenance period of generating units using a hybrid scatter-genetic algorithm. IET Gener Transm Distrib 9:22-30

10. Suresh K, Kumarappan N (2013) Coordination mechanism of maintenance scheduling using modified PSO in a restructured power market. 2013 IEEE Symposium on Computational Intelligence in Scheduling (SCIS):36-43

11. Latifi M, SEifi H, Rajabi H, Eslami M (2013) Cobweb theory based generation maintenance coordination in restructured power systems. IET Gener Transm Distrib:1253-1262

12. Edwin KW, Curtius F (1990) New maintenance scheduling method with production cost minimization via integer linear programming. Int J Electr Power Energy Syst 12:165-170

13. Yamayee Z, Sidenblad K (1983) A computationally efficient optimal maintenance scheduling method. IEEE Trans Power Appar Syst PAS-102(2):330-338

14. Dopaz JF, Merrill HM (1975) Optimal generator scheduling using integer programming. IEEE Trans Power Appar Syst PAS94:1537-1545 
15. Yare Y, Venayagamoorthy GK, Aliyu UO (2008) Optimal generator maintenance scheduling using a modified discrete PSO. In: IET Generation Transmission and Distribution, pp 834846

16. Camci F (2009) System maintenance scheduling with prognostics information using genetic algorithm. IEEE Trans Reliab 58

17. Satoh T, Nara K (1991) Maintenance scheduling by using simulated annealing method. IEEE Trans. Power Syst. 6:850857

18. Shariatzadeh F, Mandal P, Srivastava A (2015) Demand response for sustainable energy systems: a review, application and implementation strategy. Renew Sust Energ Rev 45

19. Ming Z, Lixin H, Liuqing Q, Kuo T (2010) The Risk-Based optimal maintenance scheduling for transmission system in smart grid. In: International Conference on Electrical and Control Engineering (ICECE), pp 4446-4449

20. Raghavan SS, Khaligh A (2012) Impact of plug-in hybrid electric vehicle charging on a distribution network in a Smart Grid environment. In: IEEE PES innovative smart grid technologies (ISGT) conference, pp 1-7

21. Marwali MKC, Shahidepour SM (1998) Integrated generation and transmission maintenance scheduling with network constraint. IEEE Trans Power Syst 13:1063-1068

22. Yu IK, Chou CS, Song YH (1998) Application of the ant colony search algorithm to short-term generation scheduling problem of thermal units. Int Conf Power Syst Tech 1:551556

23. Sharma C, Bahadorsingh S (2004) A MATLAB-based power generator maintenance scheduler. IEEE/PES Power Syst Conf Expo 3:1344-1348

24. Damavandi MY, Sei H, Pedram MM (2009) Generation unit maintenance scheduling considering gas network constraints. In: International conference on electric power and energy conversion systems, pp 1-5

25. Feng C, Wang X, Li F (2009) Optimal maintenance scheduling of power producers considering unexpected unit failure. IET Gener Transm Distrib 3:460-471

26. Chattopadhyay D, Bhattacharya K, Parikh J (1995) A systems approach to least-cost maintenance scheduling for an interconnected power system. IEEE Trans Power Syst 10:20022007

27. Fu Y, Shahidehpour M, Li Z (2007) Security-constrained optimal coordination of generation and transmission maintenance outage scheduling. IEEE Trans Power Syst 22:1302-1313
28. Marwali MKC, Shahidehpour SM (1999) Long term transmission and generation maintenance scheduling with network fuel and emission constraint. IEEE Trans Power Syst 14:1160-1165

29. Al-Khamis TM, Vemuri S, Lemonidis L, Yellen J (1992) Unit maintenance scheduling with fuel constraints. IEEE Trans Power Syst 7:933-939

30. Eshraghnia R, Modir Shanechi MH, Riahi R (2007) The eect of energy purchase cost in maintenance schedule of generating units based on genetic algorithm. Midterm Conf Control Autom:1-8

31. Park YS, Kim JH, Park JH, Hong JH (2007) Generating unit maintenance scheduling using hybrid PSO algorithm. In: 14th International Conference on Intelligent Systems Applications to Power Systems, pp 656-661

32. Mollahassani-pour M, Abdollahi A, Rashidinejad M (2014) Investigation of market-based demand response impacts on securityconstrained preventive maintenance scheduling. IEEE Syst J 19:1496-1506

33. Latify M, Mashhadi H, Seifi H, Sheikh-El-Eslami M (2013) Cobweb theory-based generation maintenance coordination in restructured power systems. IET Gener Transm Distrib 7:12531262

34. Condren J, Gedra TW, Damrongkulkamjorn P (2006) Optimal power flow with expected security costs. IEEE Trans Power Syst 21:541-547

35. Golmohamadi H, Ramezani M, Bashian A, Falaghi H (2014) Riskbased maintenance scheduling of generating units in the deregulated environment considering transmission network congestion. J Mod Power Syst Clean Energy 2:150-162

36. Yousefi GR, Seifi H (2004) Wheeling charges with consideration of consumer load modeling. Proc Int Conf Power systems and exposition IEEE PES:168-173

37. Morales M, Conejo J, Madsen H, Pinson P, Zugno M (2014) Integrating renewable in electricity market. Springer Publications

38. Conejo J, Carrion M, Morales M (2010) Decision making under uncertainty in electricity markets. Springer publications

39. Power Systems Engineering Research Center (Pserc) (2015) MATPOWER users' manual" (MATP" OWER 5.1)

40. Karki R, Hu P, Billinton R (2006) A simplified wind power generation model for reliability evaluation. IEEE Trans Energy Convers 21:533-540

41. Li G, Zhang XP (2011) Stochastic optimal power flow approach considering correlated probabilistic load and wind farm generation. In: IET conference on reliability of transmission and distribution networks 